\title{
Evaluation of cardiovascular disease burden and therapeutic goal attainment in US adults with chronic kidney disease: an analysis of national health and nutritional examination survey data, 2001-2010
}

Andreas Kuznik ${ }^{1,2^{*}}$, Jack Mardekian ${ }^{1}$ and Lisa Tarasenko ${ }^{1}$

\begin{abstract}
Background: For chronic kidney disease (CKD) patients, national treatment guidelines recommend a low-density lipoprotein cholesterol (LDL-C) goal $<100 \mathrm{mg} / \mathrm{dL}$ and blood pressure (BP) target $<130 / 80 \mathrm{mmHg}$. This analysis assessed the current status of cardiovascular (CV) risk factor treatment and control in US adults with CKD.

Methods: Weighted prevalence estimates of CV-related comorbidities, utilization of lipid- and BP-lowering agents, and LDL-C and BP goal attainment in US adults with CKD were assessed among 9,915 men and nonpregnant women aged $\geq 20$ years identified from the fasting subsample of the 2001-2010 National Health and Nutritional Examination Survey (NHANES). Analyses were performed using SAS survey procedures that consider the complex, multistage, probability sampling design of NHANES. All estimates were standardized to the 2008 US adult population ( $\geq 20$ years). Data were stratified by CKD stage based on presence of albuminuria and estimated glomerular filtration rate (eGFR), calculated using the Chronic Kidney Disease Epidemiology Collaboration (CKD-EPI) equation. Stage 3 CKD was subdivided into 3a (eGFR $45-59 \mathrm{~mL} / \mathrm{min} / 1.73 \mathrm{~m}^{2}$ ) and 3b (eGFR 30-44 mL/min/1.73 $\mathrm{m}^{2}$ ); Stage 5 CKD and dialysis recipients were excluded.

Results: Of the 9,915 NHANES participants identified for analysis, 1,428 had CKD (Stage 1-4), corresponding to a prevalence estimate for US adults aged $\geq 20$ years of $10.2 \%$. Prevalence of CV-related comorbidities increased markedly with CKD stage, with a $\sim 6-12$-fold increase in cardiovascular disease, coronary heart disease (CHD), stroke and congestive heart failure between CKD Stage 1 and 4; prevalence of diabetes, hyperlipidemia and hypertension increased by 1.2-1.6-fold. Use of lipid-lowering agents increased with CKD stage, from 18.1\% (Stage 1) to 44.8\% (Stage 4). LDL-C goal attainment increased from 35.8\% (Stage 1) to 52.8\% (Stage 3b), but decreased in Stage 4 (50.7\%). BP goal attainment decreased between Stage 1 and 4 (from 49.5\% to 30.2\%), despite increased use of antihypertensives (from 30.2\% to $78.9 \%$ ).
\end{abstract}

Conclusions: Individuals with CKD have a high prevalence of CV-related comorbidities. However, attainment of LDL-C or BP goals was low regardless of disease stage. These findings highlight the potential for intensive risk factor modification to maximize CV event reduction in CKD patients at high risk for CHD.

Keywords: Chronic Kidney Disease, Low-density Lipoprotein Cholesterol, Blood Pressure, Cardiovascular Risk Factors, Goal Attainment

\footnotetext{
* Correspondence: Andreas.Kuznik@pfizer.com

${ }^{1}$ Pfizer Inc, New York, NY, USA

${ }^{2}$ Global Health Economics and Outcomes Research, Pfizer Inc, 235 E 42nd St, New York, NY 10017, USA
} 


\section{Background}

Chronic kidney disease (CKD) is stratified into 5 distinct stages (Stage 1-5) based on the presence of persistent kidney damage and/or decreased glomerular filtration rate (GFR) [1,2], and affects an estimated 26 million adults in the United States [3]. It is well documented that individuals with CKD are at very high risk of cardiovascular (CV) morbidity and mortality [1,4-6]. This increased risk is highlighted by the observation that CKD patients are more likely to die of cardiovascular disease (CVD) than progress to end-stage renal disease (ESRD) [7-9]. Hence, CKD is considered a coronary heart disease (CHD) risk equivalent $[1,5,10]$.

Traditional risk factors such as dyslipidemia and hypertension are major determinants of CVD in those with CKD $[4,11,12]$. Both are prevalent among patients with Stage 1-4 CKD $[13,14]$ : depending on the patient population, up to $85 \%$ have a low-density lipoprotein cholesterol (LDL-C) $>130 \mathrm{mg} / \mathrm{dL}$ and up to $95 \%$ have a blood pressure (BP) $\geq 140 / 90 \mathrm{mmHg}$. Post-hoc analyses of $\mathrm{CV}$ outcomes trials have indicated that pharmacological treatment of dyslipidemia and hypertension reduces the risk of $\mathrm{CV}$ events in patients with CKD [15-20]. While the renoprotective effects of antihypertensive therapy in CKD are well-documented [12], recent data suggest that the pleiotropic effects of statins may also include the preservation of renal function [17,21-23]. As such, aggressive control of such modifiable CV risk factors is particularly important in this high-risk population.

Current national treatment guidelines for patients with CKD recommend an LDL-C goal of $<100 \mathrm{mg} / \mathrm{dL}$ and a BP goal of $<130 / 80 \mathrm{mmHg}[11,12]$. With respect to lipid-lowering therapy, treatment recommendations advocate the use of statins in addition to lifestyle modification to improve lipid profiles. Using National Health and Nutritional Examination Survey (NHANES) data covering the period from 2001 to 2010, this analysis assessed (1) the prevalence of CV-related comorbidities and CV risk factors, (2) the utilization of lipid-lowering and BP-lowering agents, and (3) rates of LDL-C or BP goal attainment in US adults stratified by CKD stage. A timetrend analysis of lipid and BP treatment and control in US adults with CKD was also conducted to assess linear trends in CV risk factor management over the five 2-year NHANES study cycles between 2001 and 2010.

\section{Methods}

\section{Study design}

NHANES is conducted by the National Center of Health Statistics, Centers for Disease Control and Prevention, as a cross-sectional, stratified, multistage probability sample survey of the US civilian, noninstitutionalized population [24,25]. NHANES data are derived from direct interviews regarding medical history, medication use and diet, as well as clinical examinations performed at mobile examination centers (including BP measurements) and laboratory tests (including blood and urine biochemistries).

From 1999, NHANES became a continuous survey, with no break between study cycles, and data are released in 2-year increments; this analysis used pooled data from the 5 most recent study cycles: 2001-2002, 2003-2004, 2005-2006, 2007-2008 and 2009-2010. Data from the 2001-2002 study cycle were included in this analysis to enable the assessment of linear trends in $\mathrm{CV}$ risk factor treatment and control before and after the release of current lipid and BP treatment guidelines for patients with CKD in 2003 and 2004, respectively [11,12]. NHANES 2001-2010 received approval from the National Center for Health Statistics research ethics review board, and written informed consent was obtained from all NHANES participants [24].

\section{Sample population}

From the total 2001-2010 NHANES population of 52,195 participants, after excluding participants $<20$ years of age $(n=24,611)$, participants that did not attend the mobile examination center $(n=1,276)$, participants without fasting laboratory measurements $(15,162)$, pregnant women $(\mathrm{n}=407)$, participants with missing lipid or BP data $(n=788)$ and participants with Stage 5 CKD $(n=36)$, a sample population of 9,915 participants was identified for analysis. This analysis was restricted to the fasting subsample of NHANES to enable the identification of participants with diabetes and hyperlipidemia, the definitions of which require valid fasting plasma glucose and LDL-C levels, respectively (described in further detail below). NHANES participants are randomly selected for inclusion in the fasting subsample and instructed to fast for 8 to $<24$ hours prior to blood specimens being taken for laboratory testing [25].

Data were stratified by CKD stage, categorized according to the presence of kidney damage (based on albuminuria) and level of decline in kidney function (based on estimated glomerular filtration rate [eGFR]). Albuminuria was defined as a urinary albumin-creatinine ratio of $\geq 30 \mathrm{mg} / \mathrm{g}$. eGFR was calculated from serum creatinine concentration using the Chronic Kidney Disease Epidemiology Collaboration (CKD-EPI) equation [26]: $\mathrm{eGFR}=141 \times \min (\mathrm{SCr} / \kappa, 1)^{\alpha} \times \max (\mathrm{SCr} / \kappa, 1)^{-1.209} \times$ $0.993^{\mathrm{Age}} \times 1.018$ if female $\times 1.159$ if black, where $\mathrm{SCr}$ is serum creatinine, $\kappa$ is 0.7 for females and 0.9 for males, $\alpha$ is -0.329 for females and -0.411 for males, min indicates the minimum of $\mathrm{SCr} / \mathrm{K}$ or 1 , and max indicates the maximum of $\mathrm{SCr} / \mathrm{K}$ or 1 . CKD staging used a modification of National Kidney Foundation (NKF) criteria [1]: Stage 1, albuminuria with an eGFR $\geq 90 \mathrm{~mL} / \mathrm{min} / 1.73 \mathrm{~m}^{2}$; Stage 2, 
albuminuria with an eGFR $60-89 \mathrm{~mL} / \mathrm{min} / 1.73 \mathrm{~m}^{2}$; Stage 3 was subdivided into Stage 3a, an eGFR $45-59 \mathrm{~mL} / \mathrm{min} /$ $1.73 \mathrm{~m}^{2}$, and Stage $3 \mathrm{~b}$, an eGFR $30-44 \mathrm{~mL} / \mathrm{min} / 1.73 \mathrm{~m}^{2}$; and Stage 4 , an eGFR $15-29 \mathrm{~mL} / \mathrm{min} / 1.73 \mathrm{~m}^{2}$. Individuals with Stage $5 \mathrm{CKD}\left(<15 \mathrm{~mL} / \mathrm{min} / 1.73 \mathrm{~m}^{2}\right)$ and those on dialysis were not included in the study due to the likelihood of confounding from the small number of individuals within these groups.

\section{Data collection and laboratory measurements}

All disease history and drug utilization was self-reported based on the NHANES questionnaire. CVD was a composite of self-reported CHD, stroke or congestive heart failure. CHD was identified by self-report of CHD, angina or myocardial infarction (MI). Presence of diagnosed or undiagnosed diabetes was identified by self-report of diabetes, self-reported use of insulin or oral medications for diabetes, or a fasting plasma glucose $\geq 126 \mathrm{mg} / \mathrm{dL}$. Hyperlipidemia was defined as fasting levels of LDL-C above the specific goal for each CHD risk category designated in the National Cholesterol Education Program Adult Treatment Panel III (NCEP ATP III) guidelines [27] (LDL-C level $\geq 160 \mathrm{mg} / \mathrm{dL}$ for individuals with $\leq 1 \mathrm{CHD}$ risk factor, $\geq 130 \mathrm{mg} / \mathrm{dL}$ for individuals with $\geq 2$ CHD risk factors, and $\geq 100 \mathrm{mg} / \mathrm{dL}$ for individuals with a history of CHD or CHD risk equivalents), or self-reported use of lipidlowering agents (including statins, fibric acid derivatives, bile acid sequestrants, cholesterol absorption inhibitors and other antihyperlipidemic agents). CHD risk factors included cigarette smoking, hypertension ( $\mathrm{BP} \geq 140 / 90 \mathrm{mmHg}$ or on antihypertensive medication), low levels of high-density lipoprotein cholesterol (HDL-C; $<40 \mathrm{mg} / \mathrm{dL}$ ), family history of premature $\mathrm{CHD}$ (male first-degree relative $<55$ years; female first-degree relative $<65$ years), and older age (men $\geq 45$ years; women $\geq 55$ years). CHD risk equivalents included diabetes and 2 or more risk factors conferring a 10 -year risk for CHD > 20\%; information on non-coronary forms of atherosclerotic disease (peripheral arterial disease, abdominal aortic aneurysm, and symptomatic carotid artery disease; also considered CHD risk equivalents) was not available in NHANES. BP measurements in NHANES were performed 3-4 times manually with a mercury sphygmomanometer according to a standard protocol [25]. The first reading was excluded and the remaining readings were used to compute average BP. Hypertension was defined as an average $\mathrm{BP}>130 \mathrm{mmHg}$ systolic or $>80$ $\mathrm{mmHg}$ diastolic, or self-reported use of antihypertensive agents (including $\beta$-blockers, calcium channel blockers, diuretics, angiotensin-converting enzyme inhibitors, angiotensin receptor blockers and other BP-lowering agents).

Methods for quantifying measures of kidney damage and kidney function have been described elsewhere [25]. Briefly, urinary albumin was measured using a solidphase fluorescent immunoassay. Urinary creatinine was measured by one of two methods: a Jaffé rate (kinetic alkaline picrate) method (prior to 2007) and an enzymatic (creatinase) method (from 2007 on). Serum creatinine was measured using the Jaffé rate method. Methods for determining blood lipid levels in NHANES have been described previously [25]. Briefly, total cholesterol was measured enzymatically on the basis of hydrogen peroxide generation. In 2001-2002, high-density lipoprotein cholesterol (HDL-C) was measured using two methods, heparin-manganese precipitation and a direct immunoassay, depending on the participant age and amount of specimen. From 2003, all HDL-C measurements used the direct immunoassay method. Triglyceride levels were measured after hydrolysis to glycerol. LDL-C levels were calculated from measured values of total cholesterol, triglycerides $(\leq 400 \mathrm{mg} / \mathrm{dL})$ and HDL-C according to the Friedewald calculation [25]. Plasma glucose was measured using a modified hexokinase enzymatic method [25].

\section{Definition of treatment goals}

Participants were classified as meeting current recommendations on LDL-C or BP treatment goals for patients with CKD [11,12] if their fasting LDL-C level was $<100 \mathrm{mg} / \mathrm{dL}$ or their BP was $\leq 130 / 80 \mathrm{mmHg}$. A sensitivity analysis to investigate the effect of increasing the threshold for BP goal attainment to $\leq 140 / 90 \mathrm{mmHg}$ was also performed. In participants with CKD and concomitant CVD, or CKD and concomitant diabetes, attainment of the optional LDL-C goal of $<70 \mathrm{mg} / \mathrm{dL}$ [28-30] was also examined.

\section{Statistical methods}

Statistical analyses were performed using survey analysis procedures available in SAS software version 9.22 (SAS Institute Inc., Cary, North Carolina) that take into account the complex sampling scheme of NHANES, and used sampling weights to account for differential probabilities of sample selection and non-response. The fasting sampling weights of the 9,915 participants included in the analysis were adjusted to the July 2008 US census population $\geq 20$ years of age $(n=221,419,638)$. Each 2-year fasting sample weight within an NHANES 2 -year study cycle was multiplied by the 2008 US census count and divided by the 2-year weighted total sample count from the analysis data set of persons in the 2-year study cycle. The population sizes for each study cycle were $180,717,445$ for $2001-2002$; $184,340,382$ for $2003-$ 2004; 190,068,016 for 2005-2006; 201,486,048 for 20072008; and 203,258,815 for 2009-2010. For example, the fasting sampling weight for each study participant from 2001-2002 was multiplied by $221,419,638 / 180,717,445$; the fasting sampling weight for each study participant from 2003-2004 was multiplied by $221,419,638$ / 
184,340,382; and so on for all 5 study periods. Demographic and clinical characteristics of the 2001-2010 NHANES participants with and without CKD were calculated using SURVEYFREQ. Rao-Scott chi-square $P$ values for categorical variables were obtained using SURVEYFREQ. Between-cohort $P$ values for continuous variables were obtained using SURVEYREG. Each continuous outcome was regressed on the indicator variable $C K D=1$ or No $C K D=0$, and a contrast statement was used to generate the between-cohort $P$ value. Estimated population prevalences were calculated using SURVEYFREQ and stratified by CKD stage. $P$ values for Stage 1 versus Stage 4 CKD were obtained using SURVEYLOGISTIC. Each outcome was regressed on the 5-level class variable CKD stage (Stage 1, 2, 3a, 3b or 4), and a contrast statement was used to generate the Stage 1 versus Stage $4 P$ value. Linear trends for utilization of lipid- and BPlowering agents, and rates of LDL-C or BP goal attainment, over the five 2-year survey cycles were also assessed using SURVEYLOGISTIC, including time as a continuous variable. Statistical tests were 2 -sided and a $P$-value $<0.05$ was considered statistically significant.

\section{Results}

\section{Prevalence of CKD}

Of the 9,915 NHANES participants identified from the 2001-2010 survey period, 1,428 had CKD (Stage 1-4), corresponding to a prevalence estimate for US adults aged $\geq 20$ years of $10.2 \%$. Among those persons with CKD, around half $(49.1 \% ; n=746)$ had Stage 3 CKD, comprising of $36.5 \%(n=545)$ with Stage $3 \mathrm{a}$ and $12.5 \%$ $(n=201)$ with Stage 3b CKD; 3.7\% $(n=60)$ had Stage 4 CKD.

\section{Characteristics of persons with and without CKD}

The demographic and clinical characteristics of the US adult population with CKD (Stage 1-4), based on NHANES participants from the 2001-2010 survey period, are shown in Table 1 . Those with CKD (mean \pm standard error [SE] eGFR: $\left.68.4 \pm 1.0 \mathrm{~mL} / \mathrm{min} / 1.73 \mathrm{~m}^{2}\right)$ were older; were more likely to be female and of non-Hispanic white origin; had a higher body mass index; had higher systolic but lower diastolic BP; had higher triglyceride but lower LDL-C levels; and were more likely to be taking medication for diabetes when compared with persons without CKD (mean \pm SE eGFR: $97.9 \pm 0.4 \mathrm{~mL} / \mathrm{min} / 1.73 \mathrm{~m}^{2}$ ). A comparison of the demographic and clinical characteristics of the US adult population with CKD stratified by LDL-C and BP goal attainment status is provided in Additional file 1: Table S1. Those at LDL-C goal had a lower eGFR; had lower BP and lipid levels; had higher levels of medication use; and were more likely to have a history of CVD and diabetes but less likely to have hyperlipidemia compared with those not at LDL-C goal. Similar
Table 1 Population characteristics of US adults $\geq \mathbf{2 0}$ years of age with and without CKD stage 1-4* based on NHANES 2001-2010 survey participants

\begin{tabular}{|c|c|c|c|}
\hline Characteristic & $\begin{array}{l}\text { With CKD } \\
(n=1,428)\end{array}$ & $\begin{array}{l}\text { Without CKD } \\
\quad(n=8,487)\end{array}$ & $P+$ \\
\hline Age at screening (years) & $64.2(0.7)$ & $44.5(0.3)$ & $<0.001$ \\
\hline Male (\%) & $41.7(1.5)$ & $49.5(0.5)$ & $<0.001$ \\
\hline Race/ethnicity (\%) & & & 0.001 \\
\hline Non-Hispanic white & $75.4(2.1)$ & $71.2(1.4)$ & \\
\hline Non-Hispanic black & $11.6(1.1)$ & $10.7(0.8)$ & \\
\hline Mexican American & $5.7(0.9)$ & $8.0(0.7)$ & \\
\hline Other & $7.3(1.4)$ & $10.1(0.8)$ & \\
\hline eGFR (mL/min/1.73 m²) & $68.4(1.0)$ & $97.9(0.4)$ & $<0.001$ \\
\hline \multirow[t]{2}{*}{ Body mass index $\left(\mathrm{kg} / \mathrm{m}^{2}\right)$} & $29.7(0.3)$ & $28.2(0.1)$ & $<0.001$ \\
\hline & $(n=1,372)$ & $(n=8,398)$ & \\
\hline \multicolumn{4}{|l|}{ Blood pressure (mmHg) } \\
\hline Systolic & $133.2(0.8)$ & $119.4(0.2)$ & $<0.001$ \\
\hline Diastolic & $67.5(0.6)$ & $70.2(0.2)$ & $<0.001$ \\
\hline \multicolumn{4}{|l|}{ Lipids (mg/dL) } \\
\hline Total cholesterol & $194.3(1.4)$ & $196.4(0.6)$ & 0.1 \\
\hline LDL-C & $111.4(1.1)$ & $117.6(0.5)$ & $<0.001$ \\
\hline $\mathrm{HDL}-\mathrm{C}$ & $54.4(0.5)$ & $54.0(0.2)$ & 0.6 \\
\hline Triglycerides & $142.6(2.4)$ & $124.2(1.0)$ & $<0.001$ \\
\hline Antidiabetic medication use (\%)‡§ & $21.0(1.4)$ & $4.8(0.2)$ & $<0.001$ \\
\hline
\end{tabular}

Values are weighted estimates presented as percent (standard error) or mean (standard error). Estimates were standardized to the July 2008 US census population $\geq 20$ years of age. Conversion factors for units: eGFR in $\mathrm{mL} / \mathrm{min} / 1.73 \mathrm{~m}^{2}$ to $\mathrm{mL} / \mathrm{s} / 1.73 \mathrm{~m}^{2}, \times 0.01667$; total cholesterol, LDL-C and HDL-C in $\mathrm{mg} / \mathrm{dL}$ to $\mathrm{mmol} /$ $\mathrm{L}, \times 0.02586$; triglycerides in $\mathrm{mg} / \mathrm{dL}$ to $\mathrm{mmol} / \mathrm{L}, \times 0.01129$; glucose in $\mathrm{mg} / \mathrm{dL}$ to $\mathrm{mmol} / \mathrm{L}, \times 0.05551$.

${ }^{*}$ CKD Stage 1-4 was identified by the presence of kidney damage (based on albuminuria) and level of decline in kidney function (based on eGFR), and staged using modified National Kidney Foundation criteria (see Methods). $+P$ values are for with versus without CKD; $P$ value for race/ethnicity compares the distribution of race/ethnicity categories. Rao-Scott chi-square $P$ values for categorical variables were obtained using the SAS procedure SURVEYFREQ; between-cohort $P$ values for continuous variables were obtained using the SAS procedure SURVEYREG (see Methods).

$\ddagger$ All drug utilization was self-reported.

$\S$ Any antidiabetic agents including insulin and oral medications for diabetes.

results were obtained for the $\mathrm{BP}$ goal and dual goal (LDL$\mathrm{C}$ and $\mathrm{BP}$ ) cohorts, with the exception that those at $\mathrm{BP}$ goal were younger and had a higher eGFR but lower body mass index compared with those not at BP goal.

\section{Prevalence of CV-related comorbidities and CV risk factors in persons with CKD}

Overall, the prevalence of CV-related comorbidities and $\mathrm{CV}$ risk factors was higher in persons with versus those without CKD (all $P<0.001$; Table 2). The prevalence of CV-related comorbidities in persons with CKD was high: 19.6\% had CHD; 10.3\% stroke; and 9.7\% congestive heart failure (CHF). CVD-a composite of CHD, stroke or $\mathrm{CHF}$-was prevalent in $28.4 \%$ of those with CKD. The 
Table 2 Prevalence of CV-related comorbidities and CV Risk Factors by CKD Stage in US adults $\geq 20$ years of age with CKD Stage 1-4* based on 2001-2010 NHANES participants

\begin{tabular}{|c|c|c|c|c|c|c|c|c|}
\hline \multirow[t]{2}{*}{ Variable } & \multirow{2}{*}{$\begin{array}{l}\text { No CKD } \\
(n=8,487)\end{array}$} & \multirow{2}{*}{$\begin{array}{l}\text { All CKD } \\
(n=1,428)\end{array}$} & \multicolumn{5}{|c|}{ CKD Stage: } & \multirow[t]{2}{*}{$P+$} \\
\hline & & & $\begin{array}{c}1 \\
(n=285)\end{array}$ & $\begin{array}{c}2 \\
(n=337)\end{array}$ & $\begin{array}{c}3 a \\
(n=545)\end{array}$ & $\begin{array}{c}3 b \\
(n=201)\end{array}$ & $\begin{array}{c}4 \\
(n=60)\end{array}$ & \\
\hline \multicolumn{9}{|c|}{ Cardiovascular disease history (\%)‡ } \\
\hline Cardiovascular disease§ & $6.0(0.3)$ & $28.4(1.6)$ & $9.0(2.2)$ & $31.2(3.3)$ & $30.2(2.4)$ & $49.4(4.5)$ & $51.0(6.5)$ & $<0.001$ \\
\hline Coronary heart disease\| & $4.3(0.3)$ & $19.6(1.3)$ & $6.0(1.9)$ & $22.0(2.8)$ & $21.0(2.1)$ & $32.8(4.5)$ & $36.5(5.7)$ & $<0.001$ \\
\hline Stroke & $1.9(0.2)$ & $10.3(1.1)$ & $2.5(0.8)$ & $8.8(1.8)$ & $10.2(1.4)$ & $22.5(4.3)$ & $30.3(7.1)$ & $<0.001$ \\
\hline Congestive heart failure & $1.2(0.1)$ & $9.7(0.9)$ & $3.2(1.1)$ & $7.8(1.8)$ & $7.2(1.1)$ & $27.7(3.4)$ & $27.8(4.9)$ & $<0.001$ \\
\hline \multicolumn{9}{|c|}{ Cardiovascular risk factors (\%)‡ } \\
\hline Diabetes & $8.1(0.4)$ & $31.5(1.5)$ & $36.0(3.6)$ & $32.4(3.2)$ & $24.4(2.5)$ & $38.3(4.2)$ & $44.7(6.8)$ & 0.3 \\
\hline Hyperlipidemia\# & $31.0(0.6)$ & $53.9(1.5)$ & $45.5(3.3)$ & $53.8(3.1)$ & $55.1(2.6)$ & $63.4(4.5)$ & $67.8(5.5)$ & $<0.001$ \\
\hline Hypertension ${ }^{* *}$ & $37.7(0.8)$ & $76.1(1.5)$ & $58.2(3.9)$ & $75.2(3.6)$ & $83.4(2.3)$ & $85.3(2.4)$ & $94.2(2.7)$ & $<0.001$ \\
\hline
\end{tabular}

Values are weighted estimates presented as percent (standard error). Estimates were standardized to the July 2008 US census population $\geq 20$ years of age. ${ }^{*}$ CKD Stage 1-4 was identified by the presence of kidney damage (based on albuminuria) and level of decline in kidney function (based on eGFR), and staged using modified National Kidney Foundation criteria (see Methods).

$+P$ values are for Stage 1 versus Stage 4 CKD, obtained using the SAS procedure SURVEYLOGISTIC; $P$ values for No CKD versus All CKD are all $<0.001$, obtained using the SAS procedure SURVEYFREQ (see Methods).

¥All disease history and drug utilization was self-reported.

§Cardiovascular disease was a composite of self-reported CHD, stroke or CHF.

$\|$ Coronary heart disease was identified by self-report of CHD, angina or myocardial infarction.

IDiabetes was identified by self-report, self-reported use of insulin or oral medications for diabetes, or fasting glucose $\geq 126 \mathrm{mg} / \mathrm{dL}$.

\#Hyperlipidemia was defined as LDL-C $\geq 160 \mathrm{mg} / \mathrm{dL}$ for individuals with $\leq 1 \mathrm{CHD}$ risk factor, $\geq 130 \mathrm{mg} / \mathrm{dL}$ for individuals with $\geq 2 \mathrm{CHD}$ risk factors, $\geq 100 \mathrm{mg} / \mathrm{dL}$ for individuals with CHD or CHD risk equivalents (eg, diabetes), or self-reported use of lipid-lowering agents.

**Hypertension was defined as an average BP $>130 \mathrm{mmHg}$ systolic or $>80 \mathrm{mmHg}$ diastolic, or self-reported use of antihypertensive agents.

prevalence of $\mathrm{CV}$ risk factors in persons with $\mathrm{CKD}$ was also high: $31.5 \%$ had diabetes; $53.9 \%$ hyperlipidemia; and 76.1\% hypertension. Between CKD Stage 1 and 4, there was a 6-12-fold increase in the prevalence of CVD (from $9.0 \%$ to $51.0 \% ; P<0.001$ ), CHD (from $6.0 \%$ to $36.5 \% ; P<0.001$ ), stroke (from $2.5 \%$ to $30.3 \% ; P<0.001$ ) and CHF (from $3.2 \%$ to $27.8 \% ; P<0.001$ ) (Table 2). There was a $\sim 1.2-1.6$-fold increase in the prevalence of diabetes (from $36.0 \%$ to $44.7 \%$; $P=0.3$ ), hyperlipidemia (from $45.5 \%$ to $67.8 \% ; P<0.001$ ) and hypertension (from $58.2 \%$ to $94.2 \%$; $P<0.001$ ) between CKD Stage 1 and 4 (Table 2). Of note was the marked increase in disease burden between CKD Stage 3a and 3b for CVD $(P<0.001)$, CHD $(P=0.023)$, stroke $(P=0.001)$, CHF $(P<0.001)$ and diabetes $(P=0.003)$ (Table 2).

\section{Lipid treatment and control in persons with CKD}

Overall, the self-reported use of lipid-lowering agents was higher in persons with versus those without CKD (30.4\% versus $11.8 \% ; P<0.001$; Table 3 ). The use of lipidlowering agents increased with the degree of renal impairment, from $18.1 \%$ in those with CKD Stage 1 to $44.8 \%$ in those with CKD Stage 4 $(P<0.001$; Table 3$)$. The overall proportion of persons with CKD achieving the LDL-C goal of $<100 \mathrm{mg} / \mathrm{dL}$ was $40.0 \%$. LDL-C goal attainment generally increased with CKD stage, from $35.8 \%$ in those with CKD Stage 1 to $52.8 \%$ in those with
CKD Stage 3b, but decreased in those with CKD Stage 4 (to $50.7 \%$; Table 3).

\section{BP treatment and control in persons with CKD}

Overall, the self-reported use of antihypertensive agents was higher in persons with versus those without CKD (54.4\% versus $17.4 \% ; P<0.001$; Table 3 ). The use of BPlowering medications increased between CKD Stage 1 and 4, from $30.2 \%$ in those with CKD Stage 1 to $78.9 \%$ in those with CKD Stage $4(P<0.001$; Table 3$)$. However, despite the increased utilization of antihypertensives, $\mathrm{BP}$ goal attainment to $\leq 130 / 80 \mathrm{mmHg}$ decreased between CKD Stage 1 and 4 (49.5\% in Stage 1; 30.2\% in Stage 4; $P=0.019$; Table 3 ). The overall proportion of persons with CKD achieving the BP goal of $\leq 130 / 80 \mathrm{mmHg}$ was $44.6 \%$. A sensitivity analysis increasing the threshold for BP goal attainment to $\leq 140 / 90 \mathrm{mmHg}$ found this increased the proportion of persons with CKD classified as achieving BP goal by one-third, to $66.5 \%$.

Time-trend analysis of lipid and BP treatment and control rates in persons with CKD

During the NHANES period examined, there was a significant increase in the self-reported use of lipidlowering agents by persons with CKD, from 19.5\% in 2001-2002 to $38.9 \%$ in $2009-2010(P<0.001$; Figure $1 \mathrm{~A})$. Over the same time frame, the proportion of the 


\begin{tabular}{|c|c|c|c|c|c|c|c|c|}
\hline \multirow[t]{3}{*}{ Variable } & \multirow{3}{*}{$\begin{array}{l}\text { No CKD } \\
(n=8,487)\end{array}$} & \multirow{3}{*}{$\begin{array}{l}\text { All CKD } \\
(n=1,428)\end{array}$} & \multicolumn{5}{|c|}{ CKD Stage: } & \multirow[t]{3}{*}{$P+$} \\
\hline & & & 1 & 2 & $3 a$ & $3 b$ & 4 & \\
\hline & & & $(n=285)$ & $(n=337)$ & $(n=545)$ & $(n=201)$ & $(n=60)$ & \\
\hline \multicolumn{9}{|c|}{ Lipid treatment and control (\%)‡ } \\
\hline Antihyperlipidemics§ & $11.8(0.5)$ & $30.4(1.5)$ & $18.1(2.9)$ & $31.4(2.4)$ & $33.0(2.5)$ & $40.4(4.2)$ & $44.8(7.1)$ & $<0.001$ \\
\hline $\mathrm{LDL}-\mathrm{C}<100 \mathrm{mg} / \mathrm{dL}$ & ND & $40.0(1.7)$ & $35.8(3.6)$ & $38.2(3.6)$ & $38.4(2.4)$ & $52.8(3.9)$ & $50.7(8.5)$ & 0.135 \\
\hline \multicolumn{9}{|c|}{ BP treatment and control (\%)‡ } \\
\hline Antihypertensives & $17.4(0.6)$ & $54.4(1.6)$ & $30.2(3.2)$ & $54.8(3.7)$ & $62.0(2.5)$ & $71.3(3.4)$ & $78.9(5.8)$ & $<0.001$ \\
\hline $\mathrm{BP} \leq 130 / 80 \mathrm{mmHg}$ & ND & $44.6(1.8)$ & $49.5(4.0)$ & $42.4(3.7)$ & $41.6(2.9)$ & $52.3(4.3)$ & $30.2(6.2)$ & 0.019 \\
\hline \multicolumn{9}{|c|}{$\begin{array}{l}\text { Values are weighted estimates presented as percent (standard error). Estimates were standardized to the July } 2008 \text { US census population } \geq 20 \text { years of age. ND, not determined. } \\
{ }^{*} \text { CKD Stage } 1-4 \text { was identified by the presence of kidney damage (based on albuminuria) and level of decline in kidney function (based on eGFR), and staged } \\
\text { using modified National Kidney Foundation criteria (see Methods). } \\
+P \text { values are for Stage } 1 \text { versus Stage } 4 \text { CKD, obtained using the SAS procedure SURVEYLOGISTIC; } P \text { values for No CKD versus All CKD are all }<0.001 \text {, obtained } \\
\text { using the SAS procedure SURVEYFREQ (see Methods). } \\
\text { fAll drug utilization was self-reported. } \\
\text { SAny lipid-lowering agents including statins, fibric acid derivatives, bile acid sequestrants, cholesterol absorption inhibitors and other antihyperlipidemic agents. } \\
\| \text { Any antihypertensive agents including } \beta \text {-blockers, calcium channel blockers, diuretics, angiotensin-converting enzyme inhibitors, angiotensin receptor blockers } \\
\text { and other BP-lowering agents. }\end{array}$} \\
\hline
\end{tabular}

population achieving the LDL-C goal of $<100 \mathrm{mg} / \mathrm{dL}$ also increased significantly, from $25.1 \%$ to $44.7 \%$ $(P<0.001$; Figure 1B). Similarly, the self-reported use of antihypertensive agents by persons with CKD increased significantly over the 5 study cycles, from $47.6 \%$ in 2001-2002 to $60.6 \%$ in 2009-2010 ( $P=0.002$; Figure $1 C$ ), as did achievement of the BP goal of $\leq 130 / 80 \mathrm{mmHg}$ (38.0\% in 2001-2002; $50.1 \%$ in 2009-2010; $P<0.001$; Figure 1D).

\section{Lipid and BP treatment and control in persons with CKD and concomitant CVD or diabetes}

Table 4 shows lipid and BP treatment and control rates in persons with CKD and concomitant CVD or diabetes. For those with concomitant CKD and CVD, 50.7\% reported using lipid-lowering agents and $52.8 \%$ had an LDL-C $<100 \mathrm{mg} / \mathrm{dL} ; 21.9 \%$ achieved the optional LDL-C goal of $<70 \mathrm{mg} / \mathrm{dL}$. BP treatment and control rates in this population were $72.7 \%$ and $46.3 \%$, respectively (Table 4). For those with concomitant CKD and diabetes, 44.6\% reported using lipid-lowering agents and $51.2 \%$ had an LDL-C $<100 \mathrm{mg} / \mathrm{dL} ; 17.5 \%$ achieved the optional LDL-C goal of $<70 \mathrm{mg} / \mathrm{dL}$. BP treatment and control rates in this population were $69.9 \%$ and $40.8 \%$, respectively (Table 4 ).

Dual lipid and BP goal attainment in persons with CKD, with or without concomitant CVD or diabetes

The overall proportion of persons with CKD who simultaneously achieved both an LDL-C $<100 \mathrm{mg} / \mathrm{dL}$ and a BP $\leq 130 / 80 \mathrm{mmHg}$ was $19.5 \%$. Dual lipid and BP goal attainment was achieved in $28.1 \%$ of the population with concomitant CKD and CVD, and $24.9 \%$ of those with concomitant CKD and diabetes (LDL-C $<100 \mathrm{mg} / \mathrm{dL}$; BP $\leq 130 / 80 \mathrm{mmHg}$ ).

\section{Discussion}

This analysis of NHANES data from 2001 to 2010 found that $10.2 \%$ of the US population $\geq 20$ years of age had CKD Stage 1-4, representing an estimated 22.6 million Americans. CKD - particularly advanced CKD - was associated with a high prevalence of CV-related comorbidities: nearly $50 \%$ of US adults with CKD and an eGFR $<45 \mathrm{~mL} / \mathrm{min} / 1.73 \mathrm{~m}^{2}$ had concomitant CVD. Despite this, dyslipidemia was undertreated in this high-risk population (overall treatment rate: $30.4 \%$ ). Furthermore, the proportions of individuals with CKD achieving recommended LDL-C or BP therapeutic goals were low, regardless of CKD stage. Although significant increases were seen in lipid and BP treatment and control rates over the 10 -year survey period examined, $\leq 50 \%$ of persons with CKD Stage 1-4 are currently achieving the recommended LDL-C or BP therapeutic goals. Furthermore, this analysis revealed that despite the very high-risk combination of CKD and CVD, or CKD and diabetes, dyslipidemia was undertreated in these individuals, with only around half of the CKD population with concomitant CVD or diabetes receiving any form of lipid-lowering therapy and a similar proportion achieving an LDL-C $<100 \mathrm{mg} / \mathrm{dL}$; fewer still ( 1 in 5$)$ attained the optional goal of $<70 \mathrm{mg} / \mathrm{dL}$ recommended for those individuals classified as being at very high risk of future $\mathrm{CV}$ events. Although a higher proportion of these very high-risk individuals received antihypertensive medications ( 70\%), still less than half were at BP goal $\leq 130 / 80 \mathrm{mmHg}$. Moreover, only $\sim 1$ in 5 people with CKD are achieving 


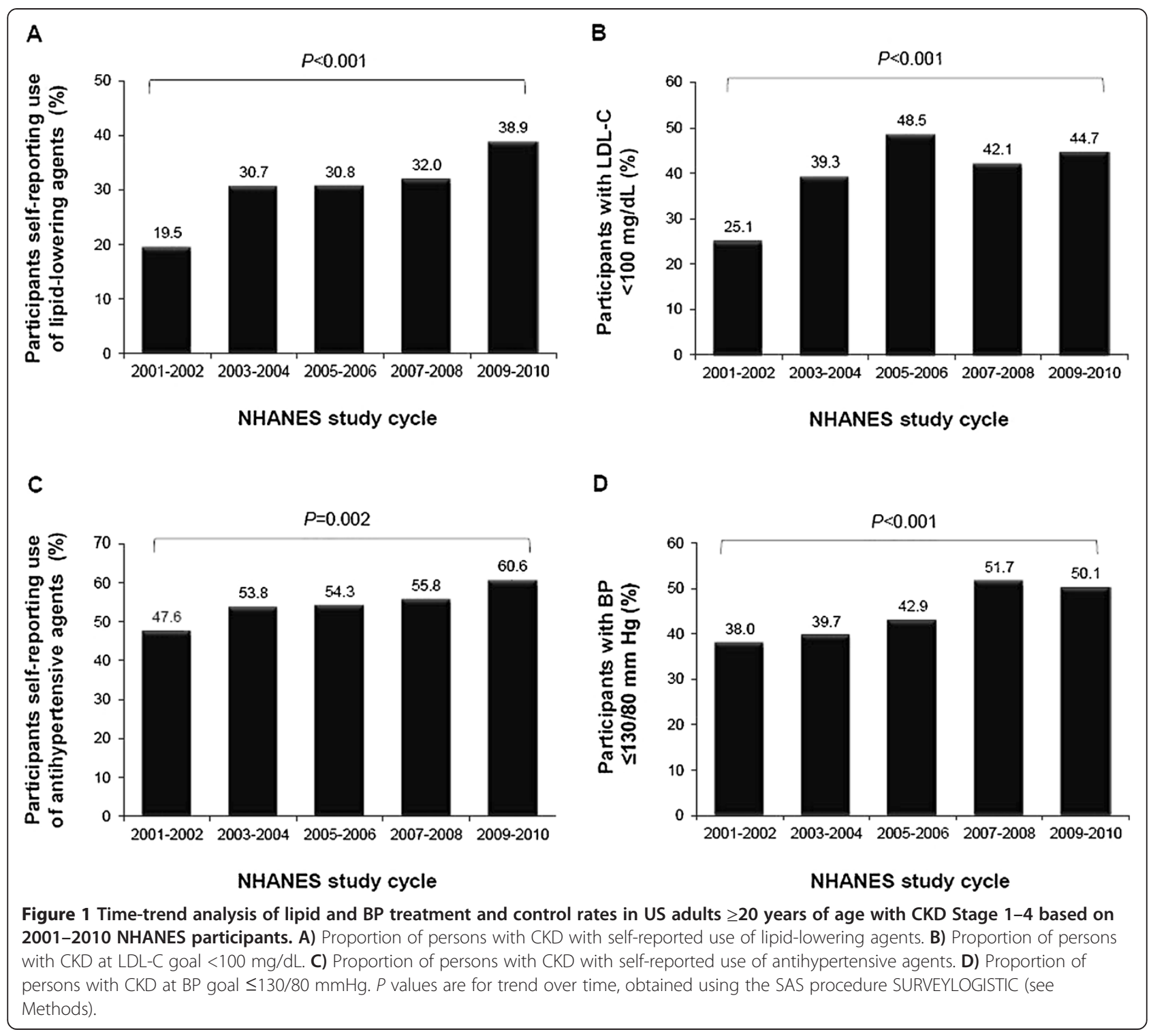

both the LDL-C and BP treatment targets simultaneously, with a slightly higher proportion $(\sim 1$ in 4$)$ of those considered to be at very high risk of future CV events (those with concomitant CVD or diabetes) at both LDL-C and BP goal. Together, these findings highlight an unmet medical need in CKD care and the potential for aggressive risk factor modification to maximize $\mathrm{CV}$ event reduction in CKD patients at high or very high risk for $\mathrm{CHD}$.

Hyperlipidemia, defined in this analysis as levels of LDL-C above the specific goal for each NCEP ATP III CHD risk category [27] or self-reported use of lipidlowering agents, was prevalent in the 2001-2010 US adult CKD population (53.9\%). In the absence of hypertriglyceridemia, national treatment guidelines for patients with CKD identify LDL-C as the primary focus of lipid-lowering therapy and advocate the use of statins in addition to therapeutic lifestyle changes to improve lipid profiles [11]. Despite these recommendations, less than one-third of individuals with CKD reported using any lipid-lowering medication (30.4\%), and just over one-third achieved the recommended LDL-C goal of $<100 \mathrm{mg} / \mathrm{dL}$ (40.0\%). Although it is not clear whether patients with very advanced renal impairment (ie, ESRD) or renal transplant recipients derive a CV benefit from statin therapy [31-33], meta-analyses [34,35] and post-hoc subgroup analyses from several large statin intervention trials [15-18,36] have indicated that aggressive treatment of dyslipidemia reduces the risk of CV events in patients with mild-to-moderate CKD. Moreover, the recent Study of Heart and Renal Protection (SHARP) - a prospective trial in 9,270 (3,023 dialysis and 6,247 predialysis) patients with CKD and no known history of MI or coronary revascularization demonstrated that LDL-C reduction with ezetimibe/ simvastatin combination therapy reduced the relative risk 
Table 4 Lipid and BP treatment and control rates in US adults $\geq 20$ years of age with CKD Stage $1-4^{*}$ and concomitant CVD or diabetes based on 2001-2010 NHANES participants

\begin{tabular}{|c|c|c|}
\hline \multirow[t]{3}{*}{ Variable } & \multicolumn{2}{|c|}{ With CKD Stage $1-4^{*}$ and: } \\
\hline & $\begin{array}{l}\text { Cardiovascular } \\
\text { Diseaset }\end{array}$ & Diabetes \\
\hline & $(n=434)$ & $(n=501)$ \\
\hline \multicolumn{3}{|c|}{$\begin{array}{l}\text { Lipid treatment and control } \\
\text { (\%)§ }\end{array}$} \\
\hline Antihyperlipidemics| & $50.7(2.3)$ & $44.6(2.7)$ \\
\hline $\mathrm{LDL}-\mathrm{C}<100 \mathrm{mg} / \mathrm{dL}$ & $52.8(2.3)$ & $51.2(2.5)$ \\
\hline $\mathrm{LDL}-\mathrm{C}<70 \mathrm{mg} / \mathrm{dL}$ & $21.9(2.0)$ & $17.5(2.3)$ \\
\hline \multicolumn{3}{|c|}{ BP treatment and control (\%)§ } \\
\hline Antihypertensives & $72.7(2.6)$ & $69.9(2.6)$ \\
\hline $\mathrm{BP} \leq 130 / 80 \mathrm{mmHg}$ & $46.3(2.7)$ & $40.8(2.9)$ \\
\hline
\end{tabular}

Values are weighted estimates presented as percent (standard error). Estimates were standardized to the July 2008 US census population $\geq 20$ years of age. *CKD Stage 1-4 was identified by the presence of kidney damage (based on albuminuria) and level of decline in kidney function (based on eGFR), and staged using modified National Kidney Foundation criteria (see Methods). +Cardiovascular disease was a composite of self-reported CHD, stroke or CHF. ¥Diabetes was identified by self-report, self-reported use of insulin or oral medications for diabetes, or fasting glucose $\geq 126 \mathrm{mg} / \mathrm{dL}$. $\S$ All drug utilization was self-reported.

\|Any lipid-lowering agents including statins, fibric acid derivatives, bile acid sequestrants, cholesterol absorption inhibitors and other antihyperlipidemic agents.

IAny antihypertensive agents including $\beta$-blockers, calcium channel blockers, diuretics, angiotensin-converting enzyme inhibitors, angiotensin receptor blockers and other BP-lowering agents.

of a major atherosclerotic event (coronary death, MI, ischemic stroke, or revascularization) by $17 \%$ (RR, $0.83 ; 95 \%$ CI, 0.74-0.94; $P=0.002$ ) versus placebo, irrespective of the severity of renal disease [37]. The apparent discrepancy between trials such as 4D or AURORA and SHARP is currently the subject of much debate within the medical community, and has centered on differences in the primary end point and rates of specific CV outcomes across the 3 trials that might explain the lack of clear benefit in the earlier trials. For example, the primary end point in the 4D trial focused on cardiac death, and sudden cardiac death - less likely to be modifiable with statin therapy accounted for $>50 \%$ of the primary outcomes in this trial [31]. This is in stark contrast with the more specific, atherosclerotic end point, and the predominance of non-fatal atherosclerotic (and, hence, statin-modifiable) outcomes, in the SHARP trial [37]. Interestingly, heterogeneity analyses across 4 prospective statin trials in renal patients (SHARP, AURORA, 4D, and the Assessment of Lescol in Renal Transplantation [ALERT] trial) found a similar effect of LDL-C-lowering therapy on risk reduction for selected vascular outcomes, including nonfatal MI, nonfatal ischemic stroke, and coronary revascularization [37]. Given the high prevalence of CV-related comorbidities and $\mathrm{CV}$ risk factors observed in this analysis of NHANES participants with CKD, aggressive LDL-C-lowering therapy to an optional goal of $<70 \mathrm{mg} / \mathrm{dL}$ may be warranted in those with multiple high-risk factors (eg, CKD plus diabetes or CKD plus established CHD), as suggested in current national treatment recommendations for patients at very high risk of future CV events [28-30]. However, we found that only $\sim 20 \%$ of those individuals with CKD and concomitant CVD or diabetes were achieving this morestringent LDL-C goal.

Hypertension (defined as an average BP >130 mmHg systolic or $>80 \mathrm{mmHg}$ diastolic, or self-reported use of antihypertensive agents) was also prevalent in the 20012010 US adult CKD population (76.1\%). Current treatment recommendations indicate that, for most patients with CKD, the use of multiple antihypertensive agents will be required to achieve a $\mathrm{BP}$ goal of $<130 / 80 \mathrm{mmHg}$ and reduce CV risk [12]. Despite this, only around half of individuals with CKD reported using any antihypertensive medication (54.4\%), and less than half achieved a BP goal of $\leq 130 / 80 \mathrm{mmHg}(44.6 \%)$. A sensitivity analysis increasing the threshold for BP goal attainment to $\leq 140 / 90 \mathrm{mmHg}$ increased the proportion of persons with CKD classified as achieving their BP goal to $66.5 \%$. The lack of conclusive evidence from randomized controlled trials as to the $\mathrm{CV}$ benefit of strict versus standard BP control [38] has sparked intensive debate on the subject of an appropriate BP goal for patients with CKD. However, the observation from our analysis that over half of all US adults with CKD are not meeting the current BP treatment goal of $\leq 130 / 80 \mathrm{mmHg}$, and one-third are not meeting the less-stringent target of $\leq 140 / 90 \mathrm{mmHg}$, indicates that suboptimal management of hypertension persists in this high-risk population.

The restriction of this analysis to the fasting subsample of NHANES due to the requirement of valid glucose and LDL-C measurements may explain the somewhat counterintuitive fall in prevalence of CKD Stage 1-4 observed between this analysis of NHANES 2001-2010 data (10.2\%; 22.6 million US adults; standardized to the 2008 US adult population) and an earlier analysis of NHANES 1999-2004 data (13.1\%; 26.3 million US adults; standardized to the 2000 US adult population) [3], as the prevalence estimates presented here were based on around three-quarters of the number of NHANES participants as the previous study ( $n=9,915$ versus $n=13,233$, respectively). Also, the use of the CKDEPI equation in this analysis versus the Modification of Diet in Renal Disease (MDRD) Study equation in the earlier analysis [3] may have also contributed to the reduced estimated CKD prevalence we observed. A comparison of the MDRD and CKD-EPI equations using the earlier NHANES 1999-2006 data $(n=16,032)$ led to a downward revision of CKD prevalence from $13.1 \%$ to $11.5 \%$ [26]. The tendency of the CKD-EPI equation to 
more accurately classify lower-risk patients into higher eGFR categories and result in lower prevalence estimates of CKD has also been documented in a number of other studies $[39,40]$. However, the most recent report from the US Renal Data System, using the CKD-EPI equation to calculate eGFR, puts the overall prevalence of CKD (including Stage 5 CKD) in the NHANES 2005-2010 population as high as $14.0 \%$ [41].

The stratification of CKD into 5 stages according to the presence of persistent kidney damage and/or level of decline in eGFR was previously based on criteria developed in 2002 by the NKF [1] and subsequently endorsed by the Kidney Disease: Improving Global Outcomes (KDIGO) Foundation [42]. However, refinements to the CKD classification system were proposed to provide a more comprehensive description of CKD severity, disease prognosis, and CV risk [43,44]. For example, the high prevalence of Stage 3 CKD [3], and potential differences in CV risk profiles within this stage $[8,45]$, led some experts to suggest subdividing this category into Stage $3 \mathrm{a}$ and $3 \mathrm{~b}$ CKD (eGFR $45-59$ and $30-44 \mathrm{~mL} / \mathrm{min} /$ $1.73 \mathrm{~m}^{2}$ ). This analysis of 2001-2010 NHANES data found that the prevalence of $\mathrm{CV}$-related comorbidities and $\mathrm{CV}$ risk factors was significantly higher in Stage 3b versus $3 \mathrm{a} C K D$, including an observed $\sim 2$-fold increase in the prevalence of CVD and stroke between Stage 3a and $3 \mathrm{~b}$, thus supporting this particular revision of the CKD classification system. Indeed, the recently released KDIGO 2012 Clinical Practice Guideline for the Evaluation and Management of Chronic Kidney Disease [2] now includes the subdivision of Stage 3 CKD, as well as the addition of albuminuria stages and diagnosis of CKD by cause, to enable more precise estimations of disease risk and prognosis in patients with CKD.

The additional economic burden associated with CVD in the context of CKD is substantial, and effective CV risk factor modification in patients with CKD has the potential to significantly reduce healthcare costs and improve patient outcomes. In 2008, costs for general (feefor-service) Medicare patients with both CKD and CVD exceeded $\$ 24$ billion and accounted for $\sim 12 \%$ of overall Medicare expenditures, despite these patients representing only $\sim 5 \%$ of the general Medicare population [46]. Patients with CKD and CVD also had per-person, per-month expenditures that were nearly double those of patients with CKD alone ( $\$ 1,687$ versus $\$ 888$, respectively) [46]. Similar observations have been made within the managed-care setting. An analysis of 13,796 patients with CKD and their matched controls from a large health-maintenance organization demonstrated that the presence of CKD-related comorbidities such as CHD and diabetes almost doubled the total cost of care in these cohorts, and the costs associated with these comorbidities were disproportionally higher in patients with concomitant CKD [47]. A recent review assessing cost effectiveness analyses of a wide range of pharmacological and non-pharmacological interventions for patients with CKD found that a high proportion of the interventions were dominant over the comparator (suggesting both improved outcomes for patients and lower costs for payors), particularly those relating to antihypertensive therapies in patients with CKD Stages 1-4 [48].

\section{Limitations}

This analysis should be interpreted within the context of the following limitations. Drug utilization and disease history in NHANES participants is obtained by selfreport and so may be subject to recall bias. Laboratory measurements were performed on single blood and urine specimens, and relied on participants selfreporting an appropriate period of fasting, the absence of which may result in confounding. The use of urinary albumin and creatinine data from a single urine specimen prevented the inclusion of "persistent" albuminuria in the definition of individuals with Stage 1 and Stage 2 CKD. It is important to note that not all NHANES participants receive routine medical care; while this allows for the generalizability of the data to the overall US population, it could be considered a limitation when interpreting lipid and BP treatment and control rates. Finally, caution should be exercised in drawing strong inferences on US population trends based on comparisons between Stage 1 and Stage 4 CKD due to the low number of participants with CKD Stage $4(n=60)$ identified from the NHANES 2001-2010 fasting subsample.

\section{Conclusion}

Although significant increases in lipid and BP treatment and control rates were observed over the past decade, these nationally representative trends suggest that continued efforts by healthcare professionals are required to achieve recommended treatment goals for CV risk factors and reduce the economic and social burden of $\mathrm{CV}$ complications associated with CKD. Given the observed high prevalence of concomitant CV comorbidities in US adults with advanced CKD, and the potential to reduce future CV events and/or progression of renal disease, traditional CV risk factors such as hypertension and dyslipidemia should be treated more intensively in this population.

\section{Additional file}

Additional file 1: Table S1. Population characteristics of US adults $\geq 20$ years of age with CKD Stage $1-4^{*}$ by LDL-C and BP goal attainment status based on NHANES 2001-2010 survey participants.

Competing interests

This study was funded by Pfizer Inc. All authors are employees of Pfizer Inc. with ownership of stock in Pfizer Inc. 


\section{Authors' contributions}

AK and LT designed the study and wrote the manuscript. JM performed the data extraction and analyses, and revised the manuscript. All authors read and approved the final manuscript.

\section{Acknowledgements}

All data used in this study were collected by the National Center for Health Statistics, Centers for Disease Control and Prevention. The authors thank Dr Daniel Wilson, MD, FACP, FCCP, at Pfizer Inc. for helpful discussions during the development of this paper. Editorial support was provided by Dr Shirley Smith, PhD, at UBC Scientific Solutions Ltd and was funded by Pfizer Inc.

Received: 4 December 2012 Accepted: 21 June 2013

Published: 27 June 2013

\section{References}

1. National Kidney Foundation: K/DOQI clinical practice guidelines for chronic kidney disease: evaluation, classification, and stratification. Am $J$ Kidney Dis 2002, 39(2 Suppl 1):S1-S266.

2. Kidney Disease, Improving Global Outcomes (KDIGO) CKD Work Group: KDIGO 2012 clinical practice guideline for the evaluation and management of chronic kidney disease. Kidney Int Supp/ 2013, 3(1):1-150.

3. Coresh J, Selvin E, Stevens LA, Manzi J, Kusek JW, Eggers P, Van Lente F, Levey AS: Prevalence of chronic kidney disease in the United States. JAMA 2007, 298(17):2038-2047.

4. Sarnak MJ, Levey AS: Cardiovascular disease and chronic renal disease: a new paradigm. Am J Kidney Dis 2000, 35(4 Suppl 1):S117-S131.

5. Sarnak MJ, Levey AS, Schoolwerth AC, Coresh J, Culleton B, Hamm LL, McCullough PA, Kasiske BL, Kelepouris E, Klag MJ, Parfrey P, Pfeffer M, Raij L, Spinosa DJ, Wilson PW: Kidney disease as a risk factor for development of cardiovascular disease: a statement from the american heart association councils on kidney in cardiovascular disease, high blood pressure research, clinical cardiology, and epidemiology and prevention. Circulation 2003, 108(17):2154-2169.

6. Tonelli M, Wiebe N, Culleton B, House A, Rabbat C, Fok M, McAlister F, Garg AX: Chronic kidney disease and mortality risk: a systematic review. J Am Soc Nephrol 2006, 17(7):2034-2047.

7. Collins AJ, Li S, Gilbertson DT, Liu J, Chen SC, Herzog CA: Chronic kidney disease and cardiovascular disease in the Medicare population. Kidney Int 2003, 64(Suppl 87):S24-S31.

8. Go AS, Chertow GM, Fan D, McCulloch CE, Hsu CY: Chronic kidney disease and the risks of death, cardiovascular events, and hospitalization. $N$ Engl J Med 2004, 351(13):1296-1305

9. Keith DS, Nichols GA, Gullion CM, Brown JB, Smith DH: Longitudinal followup and outcomes among a population with chronic kidney disease in a large managed care organization. Arch Intern Med 2004, 164(6):659-663.

10. Levey AS, Beto JA, Coronado BE, Eknoyan G, Foley RN, Kasiske BL, Klag MJ, Mailloux LU, Manske CL, Meyer KB, Parfrey PS, Pfeffer MA, Wenger NK, Wilson PW, Wright JT Jr: Controlling the epidemic of cardiovascular disease in chronic renal disease: what do we know? What do we need to learn? Where do we go from here? National kidney foundation task force on cardiovascular disease. Am J Kidney Dis 1998, 32(5):853-906.

11. National Kidney Foundation: K/DOQI clinical practice guidelines for management of dyslipidemias in patients with kidney disease. Am J Kidney Dis 2003, 41(4 Suppl 3):S1-S91.

12. National Kidney Foundation: K/DOQI clinical practice guidelines on hypertension and antihypertensive agents in chronic kidney disease. Am J Kidney Dis 2004, 43(5 Suppl 1):S1-\$290

13. Kasiske BL: Hyperlipidemia in patients with chronic renal disease. Am J Kidney Dis 1998, 32(5 Suppl 3):S142-S156.

14. Mailloux LU, Levey AS: Hypertension in patients with chronic renal disease. Am J Kidney Dis 1998, 32(5 Suppl 3):S120-S141.

15. Tonelli M, Isles C, Curhan GC, Tonkin A, Pfeffer MA, Shepherd J, Sacks FM, Furberg C, Cobbe SM, Simes J, Craven T, West M: Effect of pravastatin on cardiovascular events in people with chronic kidney disease. Circulation 2004, 110(12):1557-1563.

16. Shepherd J, Kastelein JJP, Bittner V, Deedwania P, Breazna A, Dobson S, Wilson DJ, Zuckerman A, Wenger NK, TNT (Treating to New Targets) Investigators: Intensive lipid lowering with atorvastatin in patients with coronary heart disease and chronic kidney disease: the treating to new targets (TNT) study. J Am Coll Cardiol 2008, 51(15):1448-1454.
17. Koren MJ, Davidson MH, Wilson DJ, Fayyad RS, Zuckerman A, Reed DP, ALLIANCE Investigators: Focused atorvastatin therapy in managed-care patients with coronary heart disease and CKD. Am J Kidney Dis 2009 53(5):741-750.

18. Ridker PM, MacFadyen J, Cressman M, Glynn RJ: Efficacy of rosuvastatin among men and women with moderate chronic kidney disease and elevated high-sensitivity C-reactive protein: a secondary analysis from the JUPITER (justification for the use of statins in prevention-an intervention trial evaluating rosuvastatin) trial. J Am Coll Cardiol 2010, 55(12):1266-1273.

19. Pahor M, Shorr RI, Somes GW, Cushman WC, Ferrucci L, Bailey JE, Elam JT, Applegate WB: Diuretic-based treatment and cardiovascular events in patients with mild renal dysfunction enrolled in the systolic hypertension in the elderly program. Arch Intern Med 1998, 158(12):1340-1345.

20. Mann JF, Gerstein HC, Pogue J, Bosch J, Yusuf S: Renal insufficiency as a predictor of cardiovascular outcomes and the impact of ramipril: the HOPE randomized trial. Ann Intern Med 2001, 134(8):629-636.

21. Tonelli M, Isles C, Craven T, Tonkin A, Pfeffer MA, Shepherd J, Sacks FM Furberg C, Cobbe SM, Simes J, West M, Packard C, Curhan GC: Effect of pravastatin on rate of kidney function loss in people with or at risk for coronary disease. Circulation 2005, 112(2):171-178.

22. Shepherd J, Kastelein JJP, Bittner V, Deedwania P, Breazna A, Dobson S, Wilson DJ, Zuckerman A, Wenger NK, Treating to New Targets Investigators: Effect of intensive lipid lowering with atorvastatin on renal function in patients with coronary heart disease: the treating to new targets (TNT) study. CJASN 2007, 2(6):1131-1139.

23. Vidt DG, Ridker PM, Monyak JT, Schreiber MJ, Cressman MD: Longitudinal assessment of estimated glomerular filtration rate in apparently healthy adults: a post hoc analysis from the JUPITER study (justification for the use of statins in prevention: an intervention trial evaluating rosuvastatin). Clin Ther 2011, 33(6):717-725.

24. National Health and Nutrition Examination Survey, Centers for Disease Control and Prevention (CDC), National Center for Health Statistics (NCHS): About the National Health and Nutrition Examination Survey, 2001-2010. http://www.cdc.gov/nchs/nhanes/about_nhanes.htm.

25. National Health and Nutrition Examination Survey, Centers for Disease Control and Prevention (CDC), National Center for Health Statistics (NCHS): National Health and Nutrition Examination Survey questionnaires, datasets, and related documentation, 2001-2010. http://www.cdc.gov/nchs/nhanes/ nhanes_questionnaires.htm.

26. Levey AS, Stevens LA, Schmid $\mathrm{CH}$, Zhang YL, Castro AF 3rd, Feldman HI, Kusek JW, Eggers P, Van Lente F, Greene T, Coresh J: A new equation to estimate glomerular filtration rate. Ann Intern Med 2009, 150(9):604-612.

27. Expert Panel on Detection, Evaluation, and Treatment of High Blood Cholesterol in Adults: Executive summary of the third report of the national cholesterol education program (NCEP) expert panel on detection, evaluation, and treatment of high blood cholesterol in adults (adult treatment panel III). JAMA 2001, 285(19):2486-2497.

28. Grundy SM, Cleeman II, Merz CN, Brewer HB Jr, Clark LT, Hunninghake DB, Pasternak RC, Smith SC Jr, Stone NJ, Coordinating Committee of the National Cholesterol Education Program: Implications of recent clinical trials for the national cholesterol education program adult treatment panel III guidelines. Circulation 2004, 110(2):227-239.

29. American Heart Association, American College of Cardiology: AHA/ACC guidelines for secondary prevention for patients with coronary and other atherosclerotic vascular disease: 2006 update. Endorsed by the national heart lung, and blood institute. Circulation 2006, 113(19):2363-2372.

30. National Kidney Foundation: KDOQI clinical practice guidelines and clinical practice recommendations for diabetes and chronic kidney disease. Am J Kidney Dis 2007, 49(2 Suppl 2):S12-S154.

31. Wanner C, Krane V, Marz W, Olschewski M, Mann JF, Ruf G, Ritz E, German Diabetes and Dialysis Study Investigators: Atorvastatin in patients with type 2 diabetes mellitus undergoing hemodialysis. N Engl J Med 2005, 353(3):238-248.

32. Fellstrom BC, Jardine AG, Schmieder RE, Holdaas H, Bannister K, Beutler J, Chae DW, Chevaile A, Cobbe SM, Gronhagen-Riska C, De Lima JJ, Lins R, Mayer G, McMahon AW, Parving HH, Remuzzi G, Samuelsson O, Sonkodi S, Sci D, Suleymanlar G, Tsakiris D, Tesar V, Todorov V, Wiecek A, Wuthrich RP, Gottlow M, Johnsson E, Zannad F, AURORA Study Group: Rosuvastatin and cardiovascular events in patients undergoing hemodialysis. $N$ Engl J Med 2009, 360(14):1395-1407. 
33. Holdaas H, Fellstrom B, Jardine AG, Holme I, Nyberg G, Fauchald P. Gronhagen-Riska C, Madsen S, Neumayer HH, Cole E, Maes B, Ambuhl P, Olsson AG, Hartmann A, Solbu DO, Pedersen TR, Assessment of Lescol in Renal Transplantation (ALERT) Study Investigators: Effect of fluvastatin on cardiac outcomes in renal transplant recipients: a multicentre, randomised, placebo-controlled trial. Lancet 2003, 361(9374):2024-2031.

34. Strippoli GF, Navaneethan SD, Johnson DW, Perkovic V, Pellegrini F, Nicolucci A, Craig JC: Effects of statins in patients with chronic kidney disease: meta-analysis and meta-regression of randomised controlled trials. BMJ 2008, 336(7645):645-651.

35. Navaneethan SD, Pansini F, Perkovic V, Manno C, Pellegrini F, Johnson DW, Craig JC, Strippoli GF: HMG CoA reductase inhibitors (statins) for people with chronic kidney disease not requiring dialysis. Cochrane Database Syst Rev 2009(2):CD007784. doi:10.1002/14651858.CD007784.

36. Tonelli M, Moye L, Sacks FM, Kiberd B, Curhan G: Pravastatin for secondary prevention of cardiovascular events in persons with mild chronic renal insufficiency. Ann Intern Med 2003, 138(2):98-104.

37. The SHARP Collaborative Group: The effects of lowering LDL cholesterol with simvastatin plus ezetimibe in patients with chronic kidney disease (Study of Heart and Renal Protection): a randomised placebo-controlled trial. Lancet 2011, 377(9784):2181-2192.

38. Arguedas JA, Perez MI, Wright JM: Treatment blood pressure targets for hypertension. Cochrane Database Syst Rev 2009, 3, CD004349. doi:10.1002/ 14651858.CD004349.pub2.

39. Matsushita K, Selvin E, Bash LD, Astor BC, Coresh J: Risk implications of the new CKD epidemiology collaboration (CKD-EPI) equation compared with the MDRD study equation for estimated GFR: the atherosclerosis risk in communities (ARIC) study. Am J Kidney Dis 2010, 55(4):648-659.

40. Stevens LA, Li S, Kurella Tamura M, Chen SC, Vassalotti JA, Norris KC, Whaley-Connell AT, Bakris GL, McCullough PA: Comparison of the CKD epidemiology collaboration (CKD-EPI) and modification of diet in renal disease (MDRD) study equations: risk factors for and complications of CKD and mortality in the kidney early evaluation program (KEEP). Am J Kidney Dis 2011, 57(3 Suppl 2):S9-S16.

41. US Renal Data System: USRDS 2012 Annual Data Report: Atlas of Chronic Kidney Disease and End-Stage Renal Disease in the United States. Bethesda, MD: National Institutes of Health, National Institute of Diabetes and Digestive and Kidney Diseases; 2012.

42. Levey AS, Eckardt KU, Tsukamoto Y, Levin A, Coresh J, Rossert J, De Zeeuw D, Hostetter TH, Lameire N, Eknoyan G: Definition and classification of chronic kidney disease: a position statement from kidney disease: improving global outcomes (KDIGO). Kidney Int 2005, 67(6):2089-2100.

43. Eckardt KU, Berns JS, Rocco MV, Kasiske BL: Definition and classification of CKD: the debate should be about patient prognosis. A position statement from KDOQI and KDIGO. Am J Kidney Dis 2009, 53(6):915-920.

44. Hallan SI, Orth SR: The KDOQI 2002 classification of chronic kidney disease: for whom the bell tolls. Nephrol Dial Transplant 2010, 25(9):2832-2836.

45. Brantsma AH, Bakker SJ, Hillege HL, de Zeeuw D, de Jong PE, Gansevoort RT: Cardiovascular and renal outcome in subjects with K/DOQI stage 1-3 chronic kidney disease: the importance of urinary albumin excretion. Nephrol Dial Transplant 2008, 23(12):3851-3858.

46. US Renal Data System: USRDS 2010 Annual Data Report: Atlas of Chronic Kidney Disease and End-Stage Renal Disease in the United States. Bethesda, MD: National Institutes of Health, National Institute of Diabetes and Digestive and Kidney Diseases; 2010.

47. Smith DH, Gullion CM, Nichols G, Keith DS, Brown JB: Cost of medical care for chronic kidney disease and comorbidity among enrollees in a large HMO population. J Am Soc Nephrol 2004, 15(5):1300-1306.

48. Menzin J, Lines LM, Weiner DE, Neumann PJ, Nichols C, Rodriguez L, Agodoa I, Mayne T: A review of the costs and cost effectiveness of interventions in chronic kidney disease: implications for policy. PharmacoEconomics 2011, 29(10):839-861.

doi:10.1186/1471-2369-14-132

Cite this article as: Kuznik et al:: Evaluation of cardiovascular disease burden and therapeutic goal attainment in US adults with chronic kidney disease: an analysis of national health and nutritional examination survey data, 2001-2010. BMC Nephrology 2013 14:132.

\section{Submit your next manuscript to BioMed Central and take full advantage of:}

- Convenient online submission

- Thorough peer review

- No space constraints or color figure charges

- Immediate publication on acceptance

- Inclusion in PubMed, CAS, Scopus and Google Scholar

- Research which is freely available for redistribution 